RAD Conference Proceedings, vol. 2, pp. 290-295, 2017

www.rad-proceedings.org

\title{
PHYSIOLOGICAL PROCESSES WHEN AN ELECTRICAL CURRENT PASSES THROUGH THE TISSUES AND ORGANS
}

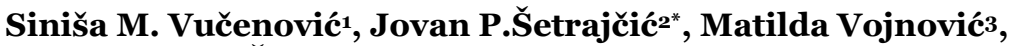 \\ Ana J. Šetrajčić-Tomić4, Ljubiša D.Džambas5 \\ ${ }^{1}$ University of Banja Luka, Faculty of Sciences, Physics, Banja Luka, Republic of Srpska, Bosnia and Herzegovina \\ ${ }^{2}$ University of Novi Sad, Faculty of Sciences, Department of Physics, Novi Sad, Vojvodina, Serbia \\ 3The Health Center, Novi Sad, Vojvodina, Serbia \\ 4University of Novi Sad, Medical Faculty, Department of Pharmacy, Novi Sad, Vojvodina, Serbia \\ 5University of Novi Sad, Medical Faculty, Department of Dentistry, Novi Sad, Vojvodina, Serbia
}

\begin{abstract}
We performed a study to investigate whether some physiological processes are caused by electrical current when passing through the tissues and organs. The basic idea of diathermia, medical treatment and therapy with alternating high frequency electric current, is to use the transformation of electric power into heat when the current goes through the tissue and internal biological environment. The important fact in this process is to avoid the massive displacement of ions, which could be potentially destructing side effect. Advantage and importance of using the alternate current (with frequency $\sim 1 \mathrm{MHz}$ ) over the direct current is explained, as well as the fact that this effect was spotted almost simultaneously by Nikola Tesla and Jaques d'Arsonval, at the end of $19^{\text {th }}$ century. This paper also explains later the cooperation between two scientists and the basic principles of diathermy - heating effect with high frequency alternate current.
\end{abstract}

Key words: Electrical current, tissue, diathermy DC-AC, high frequency AC, darsonavalization

DOI: $10.21175 /$ RadProc.2017.58

\section{INTRODUCTION}

Today, the world is unthinkable without electricity; we could postulate that electricity is actually running the modern civilization. Humanity is at the same time dependent on electricity. Imagine what would happen if for example a solar storm hit the Earth - the entire planet would go dark, consequences for our civilization would be devastating. But electricity is also, in the mean time, crucially important to various biological systems and processes. In the human body, the electric current is responsible for almost all sensor or perception processes, it controls heart beating, neurological processes and thinking. The only parameters which determine the appropriate role of electricity on physiological processes are voltage, amperage and frequency of electricity. Beside those three parameters, there is a dependency on time exposure to the electricity.

The effect of electricity acting on human body is different, depending on various properties of electricity. It could be devastating for health or essential and important for physiological processes. Some electricity parameters, when properly combined, have even a healing role for body. The frontier between healing and devastating effects of electricity is often unclear and we will try to give some overview regarding various effects of electricity to the biological tissue.

\section{FACTORS AND EFFECTS OF ELECTRICITY PASSING TROUGH HUMAN BODY}

\subsection{Electricity factors}

Electric current - is defined as a flux of charge carriers passing through the tissues. Values of alternating electric current (AC) with $50 \mathrm{~Hz}$ frequency varies in the physiological way from sensation of perception (around $0.5 \mathrm{~mA}$ ) up to values responsible for electric shock (those values depend on other factors, but the electrical current of $20 \mathrm{~mA}$ could be fatal in some circumstances).

Voltage - defined as the difference between at least two different potentials presents a possibility for electric current to flow through body, but the intensity of the electric current will be determined by the electric resistance of the body.

Body impedance - defined with resistance and frequency of applied AC. Although the resistance of body could depend on the pathway of electric current, it is considered as a constant value (if frequency is maintained on a constant value). Otherwise,

*jovan.setrajcic@df.uns.ac.rs 
impedance is highly depended on the frequency of applied AC.

Frequency - is the number of alternating periodic changes of voltage per second. Frequency of household is $50-60 \mathrm{~Hz}$ and even small values of current on that frequency could cause electric shock. On the other hand, a very high AC frequency could have healing properties, which would be later explained.

Time period of the current flow determines the energy absorbed by tissues. The longer the time - the bigger the absorbed energy (and consequently damage to the body) would be.

The pathway of the electric current is defined by the impedance and the position of the contact voltage. Obviously, the most dangerous trajectory is the one that includes the heart, although electricity could very often make damage to the other organs, too.

Other variables that could influence the electricity factors are environment temperatures, moisture, etc.

\subsection{Physiologic effects}

The effects of current are determined by the amount of the electric current that flows through the body. They could be roughly divided into two processes: the heating of tissues and the stimulation of muscles and nerves. Physiological effects are caused with relatively small amounts of current $(\sim \mathrm{mA})$. In Table 1, one can see that the usual household fuse breaker takes $10^{3}$ times more current then the one which could cause respiratory arrest.

Table 1. Estimated effects of $60 \mathrm{~Hz}$ AC current [1]

\begin{tabular}{|l|r|}
\hline \multicolumn{1}{|c|}{ Effect } & Current \\
\hline Barely perceptible & $1 \mathrm{~mA}$ \\
$\begin{array}{l}\text { Maximum current an average man } \\
\text { can grasp and "let go" }\end{array}$ & $16 \mathrm{~mA}$ \\
$\begin{array}{l}\text { Paralysis of respiratory muscles } \\
\text { Ventricular fibrillation threshold } \\
\text { Cardiac standstill and internal } \\
\text { organ damage } \\
\text { Common fuse breaker open circuit }\end{array}$ & $20 \mathrm{~mA}$ \\
\hline
\end{tabular}

How will electric current flow within the body is determined by the character of the current (AC or DC) and resistivity (impedance) of the body. Resistivity of the body is rather complex (due to the relative position on organs). For example, dry hands (i.e. dry skin) may have resistivity more then $10^{5} \Omega$, but the internal organs have about $300 \Omega$, being related to the wet and salty tissues. Thus, skin provides most of the body's protection from the electric current. Dry human skin has relatively high resistivity due to the thick outer layer of dead cells in the stratum corneum ${ }^{2}$, but this could be bypassed if there is skin breakdown from high

\footnotetext{
2 The stratum corneum is the outermost of the 5 layers of the epidermis and is largely responsible for the vital barrier function of the skin. Before the mid-1970's the stratum corneum was thought to be biologically inert, like a thin plastic sheet protecting the more active lower layers of the skin. In the past 30 years, and especially the past 5 years, scientists have discovered that the biological and chemical activity of the stratum corneum is very intricate and complex.
}

291 voltage, a cut, a deep abrasion, or immersion in water. At voltage of $500 \mathrm{~V}$ (or more), high resistance of the skin breaks down [2]. Resistivity of the body is significantly lowered so the current is increasing, at any voltage. This could result with in deep tissue injury to the muscles, nerves or other organs. "Large" voltage applied could result in electroporation or cell membrane damage. "Large" is between quotation marks on purpose, because electroporation will occur with $20 \mathrm{kV}$ from hand to hand (or head to foot), but only $120 \mathrm{~V}$ with the end of power cord in a child's mouth. Electroporation is defined with voltage applied per unit length of tissue.

Heat is the consequence of the electric current flow through the body. In accordance with Joules law, heat produced in the body is proportional to the square of the voltage, but the physiological effect differs on fact whether the current is applied, direct or alternating. On household frequency $(50 \mathrm{~Hz})$, if the current intensity is high enough, one can feel electric shock all the time as contact is made. The result of shock state is muscle contraction and loss of voluntary movements. With high enough amplitude of electric current, ventricular fibrillation occurs. In the DC regime, one can feel an electric shock only when the circuit is made or broken, i.e. while the contact is maintained - there is no sensation of shock (except the feeling of warmth, while the current travels through the body) [3].

High voltage $(>600$ V) electric current could produce arcs, when electricity passes through the air. In that case the arc doesn't have to contact a person, but the heat of the arc could produce serious burns (or from the burning clothes torched by the arcs). Also, high voltage arcs could produce shock waves, they could be strong enough to throw a person, rupture eardrums, or even cause internal organs' contusion. In the case in which the electric arc contacts the person (similar to the case when the electric conductor contacts the body), the electric current flows through the body and produces injuries. Those injuries include the conditions that must be watched over the time (like myoglobinuria, coagulopathy, compartment syndrome, etc.). There are other signs showing that electric current flowed through the body: high voltage generally produces full thickness burns, size of the pinhead, and sometimes multiple (due to sparkling).

Low voltage $(<600 \mathrm{~V})$ AC electric current could cause the hand to involuntarily grip conductor and that amount of current is referred to as let-go current [4]. For example, most adults will be able to let go of the energized cable with the current of less than $6 \mathrm{~mA}$, but at the current of $22 \mathrm{~mA}$, more than $99 \%$ adults will not be able to let go. This effect is caused by the simultaneous (alternation) of flexion and extension of the muscles; however, muscles of flexion are stronger and this makes the person unable to voluntary let go. Moreover, as long as the contact is continued, the subject is tightening his grip on a conductor, contact resistance is lowered, so the alternating current continues to flow, repetitively stimulates nerves and muscles, resulting in sustained contraction.

Although, in the AC regime, let-go threshold is surely $<100 \mathrm{~mA}$, some authors claim that, in the DC regime below $300 \mathrm{~mA} \mathrm{rms}$, the let-go phenomenon does not exist and that above $300 \mathrm{~mA}$ letting go may be impossible. Also, the threshold for ventricular 
fibrillation for DC current shocks longer than $2 \mathrm{sec}$. is $150 \mathrm{~mA}$. The same effect in the $\mathrm{AC}$ regime $(60 \mathrm{~Hz})$ is obtained with a $50 \mathrm{~mA}$ current $[3,5]$.

When a person touches the conductor with $10 \mathrm{kV}$ $\mathrm{AC}$, the potential outcomes could be that the person grasps the conductor more tightly or (more likely) that the person propels away from the conductor. Which of these scenarios will occur depends on the body (hand) position relative to the conductor [6].

\section{DiATHERMIA}

Electric current flow through the body doesn't have to have a damaging or devastating effect [7]. In fact, when DC (galvanic) current flows through the body, ions displace (following the electric field established inside the body) and electrolytic effects occur. In that process heat is generated, with amount proportional to the square of the current amplitude, and linearly proportional to the resistance (impedance) of the body. However, natures of electricity (AC or DC) will determine physiological effects. To heat up tissue with DC one has to apply 2-4 A, but in AC regime with household frequency of $50 \mathrm{~Hz}$, only few $\mathrm{mA}$ will be sufficient, in fact $\sim 10 \mathrm{~mA}$ produce strong pain and muscle contractions. Apparently, the key parameter is the frequency in AC regime. Experiments show that high frequency $\mathrm{AC}(>20 \mathrm{kHz})$, even with very high voltage, do not lead to massive ion displacement, muscle contraction or nerve stimulation. The reason for that is lack of time, in all cases. Nerve stimulation requires some time (to produce the stimulation effect). Ions in body are lagging and too inert to "follow up" high frequencies. They simply do not have enough time to penetrate through the neuron membrane and produce action potential. Limit time for neuron stimulation is $\sim 0,1 \mathrm{~s}$, which is much longer than half time of one cycle of $\mathrm{AC}(>20 \mathrm{kHz})$ frequencies. The ions could only vibrate and produce heat. This is exactly the same with the muscles as well; they do not have time to follow high frequencies to contract.

The term "Diathermia" was introduced by a German physician K. F. Nageschmidt in 1909. And the term originates from the Greek therma (heat) and dia (passing through), which in direct translation means warming-up. Diathermia is generally applicable in physical therapy and surgery. In physical therapy (or electrotherapy), electrical current warms up internal (or external) organs and in electrosurgery (or high frequency electrotomy), it is used for bloodless removing, incising or destroying tissues. Electrosurgery is used for the prevention and stopping excess bleeding in traumatized tissues, and is also often used in eye surgery and neurosurgery, where it is needed for stopping the bleeding in thin blood vessels. Also, diathermy is very often used as a surgery method in cancer removal on the cervix.

In physical therapy, diathermy refers to heating up internal tissues using high frequency alternating current. Diathermy could be divided to long-wave, short-wave and micro-wave diathermy [8].

\subsection{Long-wave diathermy}

Frequencies of $\mathrm{AC}$ in long-wave diathermy are order of magnitude $\sim 1 \mathrm{MHz}$, with electric current amplitude 1-2 A. Electrodes are applied directly on the surface of the body with the longitudinal or transversal way of applying electrodes. In the transversal way of applying of electrode (Fig. 1), tissues of different resistance form a circuit with the serial connection of resistances, and due to the Joule's law, released heats are directly proportional to the resistance of tissues, i.e. most heated will be the tissues with the largest resistivity:

$$
\frac{Q_{1}}{Q_{2}}=\frac{R_{1}}{R_{2}} .
$$

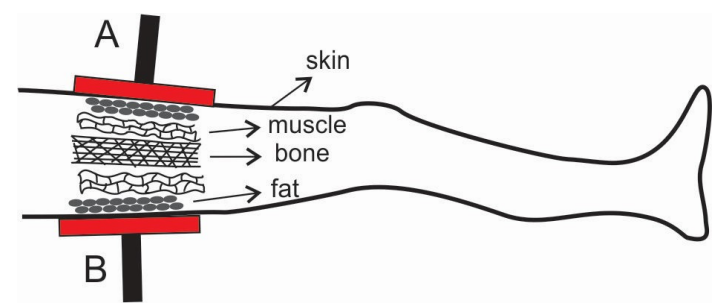

Figure 1. Transversal way of applying electrodes (A and B) directly to the human leg

In the longitudinal way of applying of electrodes (Fig. 2), tissues with different resistivity form an electrical circuit with parallel connected resistances, so the most heated will be the smallest resistance:

$$
\frac{Q_{1}}{Q_{2}}=\frac{R_{2}}{R_{1}} .
$$

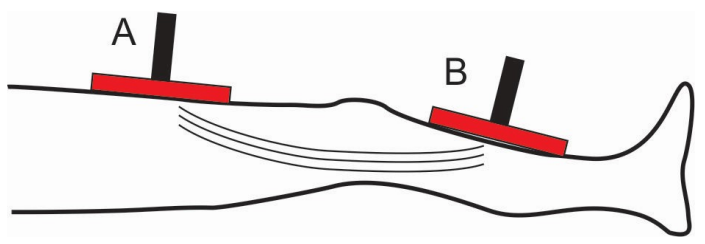

Figure 2. Longitudinal way of applying electrodes (A and B) directly to the human leg

Let us limit ourselves to the transversal applying of electrodes. On Fig. 3, the equivalent electric circuit is shown and one can see that, beside the thermal (or Ohm's) resistance, the skin has also capacitive resistance (or capacitive reactance), which are in the case of high frequencies $(\sim 1 \mathrm{MHz})$ comparable $\left(X_{\mathrm{c}} \sim R\right)$. In that case, skin will be not the most heated, although it has the largest resistance. The most heated will be internal tissues.

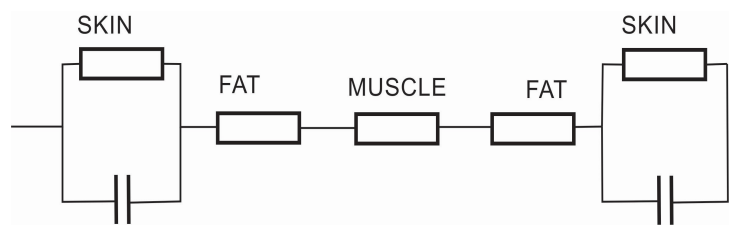

Figure 3. Equivalent electric circuit of long-wave diathermy

\subsection{Short-wave diathermy}

In this type of diathermy even higher frequency alternating current $\sim 30 \mathrm{MHz}$ is used. Because of such high frequencies, the electrodes must keep away from 
the skin surface, otherwise, sparks could occur. This type of diathermy is often referred to as the electric field diathermy. On Fig. 4, the equivalent electric circuit of the transversal applied electrodes in shortwave diathermy is shown. One can see that because of air layer between electrodes and the body, capacitance must be taken into account. However, on such high frequencies, capacitive reactance of internal tissues is now comparable with Ohm's resistance.

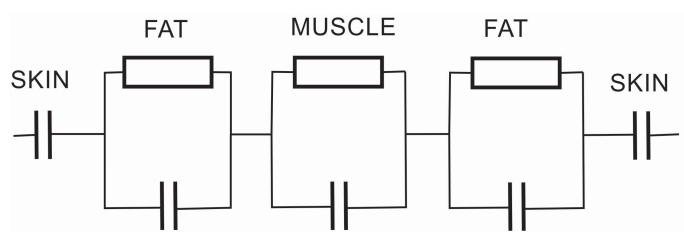

Figure 4. Equivalent electric circuit of short-wave diathermy

These facts could explain some advantage of the short-wave diathermy over the long-wave diathermy. This is evident when heating internal tissues coated with fat layer. If we use long-wave diathermy, the internal tissue will not heat up, being dielectrically shielded with layer of fat. However, using short-wave diathermy, as we have seen on Fig. 4, capacitive reactance and Ohm's resistance are comparable $\left(X_{\mathrm{c}} \sim\right.$ $R$ ) and part of the current will flow through the tissue too, and consequently warm it up. One more advantage with short-wave diathermy is that the lines of the current field are distributed more homogeneously then with long-wave diathermy.

\subsection{Micro-wave diathermy}

In this type of diathermy, instead of electrodes, a small dipole antenna is used, which is on Fig. 5 marked with (A). The antenna is placed in the focus of the parabolic reflector (B).

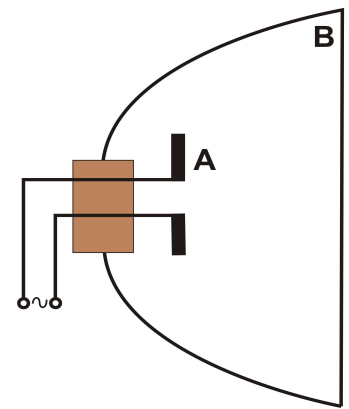

Figure 5. Scheme of micro-diathermy device

Produced microwaves penetrate inside the body 6-8 $\mathrm{cm}$ through surface tissue layers and heat up internal tissues. Micro-wave diathermy operates on the exactly same mechanism as micro-wave ovens, which are used worldwide in kitchens for fast food cooking or heating up. The mechanisms will be explained in the next chapter.

\subsection{Mechanisms of thermogenesis in diathermy}

High frequency alternating current produces electromagnetic radiation. Interaction of produced radiation and biological environment depends on the type of diathermy, i.e. on the frequency of the current. The processes involved in interaction are:

- Free ions oscillation - this is the leading mechanism of thermogenesis in long-wave diathermy. In the biological environment, ions in liquids (water) begin to vibrate under the influence of high frequency field and generate heat (due to the friction). This mechanism is responsible for all electro-conductive biological materials, which contain ions.

- Polarization of dielectric - this mechanism becomes dominant with the further increase of frequencies, i.e. with short-wave diathermy. However, the first mechanism (ion oscillations) could not be excluded and still exists. The shortwave diathermy could warm-up electrically nonconductive biological materials (dielectrics), which are represented with dielectric permittivity.

- Rotation of dipoles of water molecules - this is the main mechanism in micro-wave diathermy. Thermogenesis is achieved by friction of water molecules in the biological medium wherein water molecules rotate.

\subsection{Harmful effects of high frequency $A C$}

Humans do not have heat receptors inside the body (in fact, they are not needed) because they are distributed on the skin surface. That is the reason why we do not feel pain with diathermy. Pain is the main physiological sign for an alarming state and one should be very careful when diathermy is applied. This is especially important with micro-wave diathermy, which is the strongest one, and it should be applied with caution in the regions with reduced blood circulation. It was experimentally demonstrated that micro-wave radiation could cause eye cataract to animals [9]. High risks of micro-wave exposition have workers in radio-television industry and military. Also, the risk is very high with people who operate with MASER, because it is a very intensive source of microwaves. A biological effect of micro-waves depends on the absorption characteristics of biological tissues. At frequencies higher than $150 \mathrm{MHz}$, absorption becomes significant. Lenses of the human eyes are particularly sensitive to the frequencies around $3000 \mathrm{MHz}$, which could yield the eye cataract. At higher frequencies, skin becomes more sensitive, similarly as it is on infra-red radiation. Effects of micro-wave radiation become more significant if temperature increases. It is known that cells and tissues die out on temperatures around $43^{\circ} \mathrm{C}$. Heat effects of micro-wave radiation are harmless if the energy which the tissue absorbs is distributed on evaporation, heat radiation and heat conduction. The upper limit energy dose for absorption is around $10 \mathrm{~mW} / \mathrm{cm}^{2}$. However, even doses below that may result in decreased sperm motility, and this is why this method cannot be considered "harmless" [10].

In the late 80's of the last century, researchers from the Soviet Union published series of papers with microwave non-thermal effects on humans and suggested a dose which is 1000 times smaller than the dose allowed today in the US. They reported non-thermal effects which refer to the influence of micro-wave radiation on neurological system, exhibited in human fatigue, overly excited states and insomnia. These states are noticed 
on staff operating with high frequency radio technique. Beside that, non-thermal effects are also noticed on rabbit EEG.

\subsection{Tesla and d'Arsonval contribution to diathermy}

Nikola Tesla was experimenting with the highfrequency currents and developed transformation for the production high voltage. That transformer is today known as Tesla coil, and high frequency currents are referred as Tesla's currents. Tesla was the first who noticed that high-frequency currents could warm-up internal tissues of human body, but in such a way that skin does not warm up too much [11-13]. The wavelengths which produce those effects were longer of the longest radio-wave wavelengths. Tesla wrote his observations in 1891, and pointed these phenomena up, recommended it for medical potential usage. In that sense, Tesla laid down the groundwork for diathermia, being the first who discovered this effect.

At about the same time as the Tesla, French scientist Jacques Arsen d'Arsonval was exploring the impact of high-frequency currents in the human body and its heating. Although a little later than Tesla, he reported this phenomenon in front of the Paris society of biologists. In honor of d'Arsonval, this method of treatment was named "darsonvalization". According to one source, having heard that d'Arsonval attributed exclusively self discovery of this phenomenon, Tesla went to Paris, where he met with D'Arsonval. According to other sources, Tesla already was at that time in France, where he gave his famous lecture in Paris in 1892. Tesla took the opportunity to meet with the d'Arsonval, the scientist who had investigated the same phenomenon. Regardless, from this meeting Tesla and D'Arsonval created a friendship and later scientific cooperation, not only in the field of diathermy, but also in other areas which were jointly explored. Tesla was pleased with the fact that d'Arsonval used his system to obtain HF current, i.e. Tesla coil transformer, and that d'Arsonval mentioned this in his works, notes and demonstrations.

\section{CONCLUSION}

Effects of electricity flow through the biological environment are various. They depend generally on the mode of the current flow (direct or alternating current), the magnitude of the current, voltage and frequency (in the case of $\mathrm{AC}$ ). Biological and physiological effects beside the above-mentioned one depend on the pathway of the electric current and time of the flow. Consequences of exposure to the electric current flow or electromagnetic radiation produced could be wide: from healing to devastating.

Diathermy is one of the helpful methods of using alternating current for medical treatment, but only if used in the right way.

Acknowledgement: This paper was partly financed by the Ministry of Education, Sciences and Technological Development of the Republic of Serbia (Grand Nos. ON-171039 and TR-34019) and the Ministry of Science and Technology of the Republic of Srpska (Grant No: 19/6-O20/961-16/15) as well as and the Provincial Secretariat for Science and Technological Development of AP Vojvodina (Grant 114-451-2092).

\section{REFERENCES}

1. The National Institute for Occupational Safety and Health. (May 1998.). NIOSH Publications No. 98-131: Workers deaths by electrocution. Retrieved from:

https://www.cdc.gov/niosh/docs/98-131/pdfs/98131.pdf Retrieved on: Jan. 17, 2017

2. S. Grimnes, "Dielectric breakdown of human skin in vivo," Med. Biol. Eng. Comput., vol. 21, no. 3, pp. 379381, May 1983.

DOI: $10.1007 / \mathrm{BFO} 2478510$ PMid: 6876915

3. R. M. Fish, L.A. Geddes, "Conduction of Electrical Current to and through the Human Body: A Review," ePlasty, vol.9, pp. 407-42, Oct. 2009.

PMid: 19907637 PMCid: PMC2763825

4. C. F. Dalziel, "Effect of electric shock on man," IRE Trans. Med. Electron., vol. PMGE-5, pp. 44-62, Jul. 1956. DOI: 10.1109/IRET-ME.1956.5008573

5. T. Bernstein, "Investigations of alleged appliance electrocutions and fires caused by internal generated voltage," IEEE Ind. Appl., vol. 25, no. 4, pp. 664-668, Jul. 1989.

DOI: $10.1109 / 28.31244$

6. Electrical Trauma, R. C. Lee, E. G. Cravalho, and J. F. Burke, Eds., 1st ed., Cambridge, UK: Cambridge University Press, 1992.

7. A. M. Vučenović, D. Lj. Mirjanić, "Tesla - dijatermija i darsonvalizacija," u Ideje Nikole Tesle Knjiga X/6, D. Lj. Mirjanić, Ur, Banja Luka, BiH: Akademija nauka umjetnosti Republike Srpske, 2006, str. 51-61.

(A. M. Vučenović, D. Lj. Mirjanić, "Tesla - Diathermy and Darsonvalization," in The Ideas of Nikola Tesla Book $X / 6$, D. Lj. Mirjanić, Ed.,Banja Luka, B\&H: Academy of Sciences and Arts of the Republic of Srpska, 2006, pp. 51-61.)

8. Medicinska enciklopedija, A. Šercer, Ur, Zagreb, Jugoslavija: Jugoslavenski leksikografski zavod, 1967. (Medical Encyclopedia, A. Šercer, Ed., Zagreb, Yugoslavia: Jugoslavenski leksikografski zavod, 1967.)

9. L. Daily Jr, K. G. Wakim, J. F. Herrick, E. M. Parkhill, W. L. Benedict, "The effects of microwave diathermy on the eye: An experimental study," American Journal of Ophthalmology, vol. 33, no. 8, pp. 1241-1254, Aug. 1950.

DOI: 10.1016/0002-9394(50)90996-2

10. N. H. Steneck, H. J. Cook, A. J. Vander, G. L. Kane, "The origins of U.S. safety standards for microwave radiation," Science, vol. 208, no. 4449, pp. 1230-1237, Jun 1980.

DOI: $10.1126 /$ science.6990492

PMid: 6990492

11. N. Tesla, "High frequency oscillators for electrotherapeutic and other purposes," The Electrical Engineer, vol. 26, no. 550, pp. 477-481, Nov. 1898. Retrieved from:

http://www.tfcbooks.com/tesla/1898-11-17.htm Retrieved on: Jan. 13, 2017

12. D. J. Rhees, "Electricity -The Greatest of All Doctors: An Introduction to "High Frequency Oscillators for Electro-Therapeutic and Other Purposes", Proc. IEEEXplore, vol. 87, no. 7, pp. 1277-1281, Jul. 1999. DOI: $10.1109 /$ jproc.1999.771078

13. N. Tesla, "Art of transmitting electrical energy through the natural mediums," U. S. Patent 787 412, Apr. 18 1905. 
Retrieved from:

https://teslauniverse.com/nikola-tesla/patents/us-

patent-787412-art-transmitting-electrical-energy-

through-natural-mediums

Retrieved on: Jan. 13, 2017 